\title{
Systems biology: An emerging strategy for discovering novel pathogenetic mechanisms that promote cardiovascular disease
}

${ }^{1}$ Division of Cardiovascular Medicine, Department of Medicine, Brigham and Women's Hospital and Harvard Medical School, Boston, MA, USA

2 Department of Cardiology, Boston VA Healthcare System, Boston, MA, USA

*Email: bmaron@partners.org http://dx.doi.org/

10.21542/gcsp.2016.27

Submitted: 14 May 2016 Accepted: 12 September 2016 (C) 2016 The Author(s), licensee Magdi Yacoub Institute. This is an open access article distributed under the terms of the Creative Commons Attribution license CC BY-4.0, which permits unrestricted use, distribution and reproduction in any medium, provided the original work is properly cited.
Bradley A. Maron ${ }^{\mathbf{1}, 2 *}$, Jane A. Leopold ${ }^{\mathbf{1}}$

\section{ABSTRACT}

Reductionist theory proposes that analyzing complex systems according to their most fundamental components is required for problem resolution, and has served as the cornerstone of scientific methodology for more than four centuries. However, technological gains in the current scientific era now allow for the generation of large datasets that profile the proteomic, genomic, and metabolomic signatures of biological systems across a range of conditions. The accessibility of data on such a vast scale has, in turn, highlighted the limitations of reductionism, which is not conducive to analyses that consider multiple and contemporaneous interactions between intermediates within a pathway or across constructs. Systems biology has emerged as an alternative approach to analyze complex biological systems. This methodology is based on the generation of scale-free networks and, thus, provides a quantitative assessment of relationships between multiple intermediates, such as protein-protein interactions, within and between pathways of interest. In this way, systems biology is well positioned to identify novel targets implicated in the pathogenesis or treatment of diseases. In this review, the historical root and fundamental basis of systems biology, as well as the potential applications of this methodology are discussed with particular emphasis on integration of these concepts to further understanding of cardiovascular disorders such as coronary artery disease and pulmonary hypertension. 


\section{INTRODUCTION}

The current era of human health and disease research is defined, in part, by an explosion of technology that permits the measurement of biological data on a grand scale ${ }^{1}$. Increased availability, cost-effectiveness, and access to gene chip arrays, whole genome sequencing, metabolomic platforms, and next generation RNAseq among other approaches has resulted in the application of these methodologies to profile the genetic and molecular signature of virtually all biological mediums ${ }^{2,3}$ across normal and disease states alike ${ }^{4}$. The magnitude of data derived from these methods, which in one recent epigenetic study of myocardial infarction (MI) included an analysis of the protein-coding regions for 9,793 patient genomes and single nucleotide variants in 64,132 samples ${ }^{5}$, and the accelerating rate by which these methods are utilized in research have outpaced the evolution of analytical strategies needed for their optimal interpretation. Specifically, approaches that rely heavily on reductionism, such as association studies, cannot account adequately for the complexity inherent to datasets of this scale ${ }^{1}$.

Network theory, in turn, leverages mathematical modeling to quantify multiple, simultaneous interactions between variables (e.g., interactome). This method allows for the graphical depiction of relationships across a range of subcellular components (e.g., protein-protein, mRNA-protein, miRNA, others), and, therefore, is not limited by a particular cell type, species, or pathway ${ }^{6}$. Organizing networks further according to connectivity patterns provides a hierarchical basis of the associations within parts of a pathway or between pathways (Figure 1). Enriching networks by integrating gene sets linked to a specific pathophenotype may be used to narrow assessments of interaction clusters ${ }^{7}$. Overall, these strategies allow for a robust, but structured approach to integrating, depicting, and analyzing big data for the purposes of understanding better the interactions that underlie complex pathophenotypes.

A)
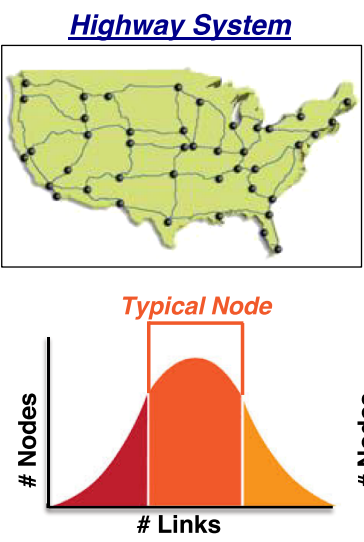

B)

Airline System
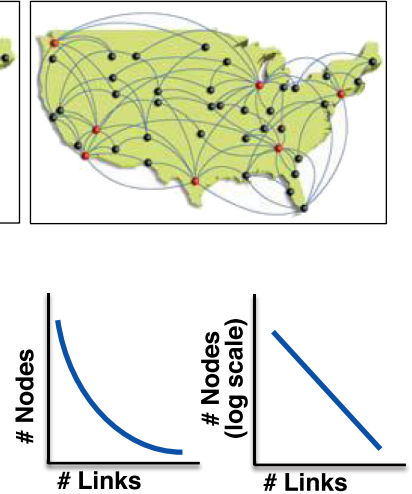

C)

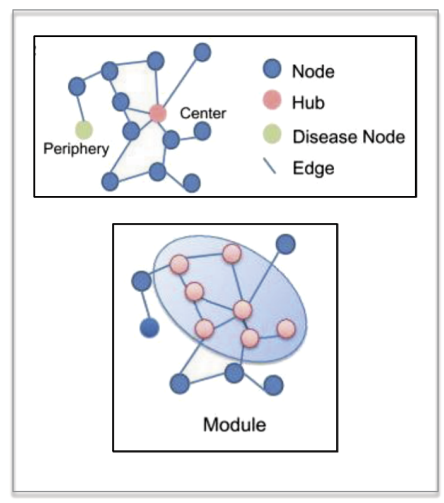

Figure 1. Network topography. (A) In a random network, the majority of nodes shares a similar number of links, and is analogous to the United States highway system in which cities are represented as nodes and interconnecting roads are represented as links. (B) In non-random networks, such as in biological systems, and, as is represented in this illustration the hub-spoke system of air travel patterns, a minority of nodes are highly connected. (C) This characteristic establishes a hierarchy based on node connectivity, which is grouped by convention in ascending order of complexity as: node, hub, module and neighborhood. These levels of connectivity, in turn, may be topographical within a network, indicate a common biological function, or grouped according to association with diseases. Figure adapted from $m^{6,37}$ with permission pending. 


\section{HISTORICAL PERSPECTIVE: REDUCTIONISM IN SCIENCE}

The French philosopher, mathematician, and physicist René Descartes is often referred to as the father of reductionism, based largely on his "Rules for the direction of the mind" written originally in $1628^{8}$, which posited 12 rules of scientific methodology. Among them, rules $\mathrm{V}$ and $\mathrm{VI}$ stipulated problem resolution is best achieved through 'intuitive apprehension of all those that are absolutely simple' and if 'obscure propositions are reduced step by step to those that are simpler.' Descartes applied this rationale to his workings that would ultimately serve as the basis for contemporary geometry, algebra, and physics. In fact, this form of deductive, rule-based reasoning was utilized by many of the great scientists and meta-scientists from the classical and contemporary eras, including Galileo Galilei (astronomy; 1564-1642), Sir Isaac Newton (physics; 1643-1727), Immanuel Kant (philosophy, 1724-1804), and, perhaps most relevant to biology, Sir Charles Darwin in his theory of natural selection (1809-1882).

In the latter part of the 2oth century, however, some challenged the appropriateness of law-based theory to biological sciences ${ }^{9}$. The reasoning for this skepticism was based, in part, on the identification of the following dilemmas: (i) reductionism implies that rules affect all components of a system similarly, which is unlikely to be the case in living organisms in vivo, and (ii) the sole focus of an analysis on fundamental components of a biological system may not be possible or warranted. For example, assessing phenotype expression according to genetic variability alone does not account for post-transcriptional regulation of RNA or post-translational modification of proteins, despite the staggering frequency of these events reported in proteome studies ${ }^{10}$ and the importance of these regulatory mechanisms in determining physiologic and disease states $^{11-13}$. Furthermore, reductionist methodologies may have a number of important unintended consequences in applied experimental biology. By narrowing the scope of study solely to a single pathway or specific interaction between two intermediaries, the effects of perturbations to the larger system are often unaccounted for (or overlooked). This, in turn, has important ramifications when considering the translational relevance of a drug or effector from studies in vitro to investigations in vivo or clinical trials. It has been proposed, for example, that this principal may underlie the failure of folic acid and B-vitamin supplementation to abrogate the cardiovascular risk associated with hyperhomocysteinemia ${ }^{14}$ despite numerous epidemiologic reports in patients supporting mechanistic data demonstrating that folic acid treatment limits the adverse effect of homocysteine on endothelial dysfunction, atherogenesis, and thrombosis ${ }^{15}$. In these studies, however, the pro-proliferative, tumorigenic, and diverse metabolic effects of folic acid/B-vitamins were not generally considered ${ }^{16}$ (Figure 2). Thus, the possibility remains that those or other untested (and potentially detrimental) consequences of these therapies may account for the failure of folic acid/B-vitamin therapy to improve outcome in randomized clinical trials ${ }^{17}$.

\section{NETWORK THEORY IN APPLIED BIOLOGICAL SCIENCES}

In random networks, the density of links (e.g., connections) between nodes (e.g., entities) follows a Poisson (normal) distribution (Figure $1 \mathrm{~A}$ ). In this configuration, the majority of nodes share a similar degree of connectivity, and highly connected nodes are not common ${ }^{6,18}$. However, in biological networks (among other naturally occurring network types), the relationship between nodes and links appears to be quite different. Jeong and colleagues ${ }^{19}$ constructed a protein-protein interactome based on S. cerevisiae proteome data and demonstrated the probability that a given protein interacts with other 


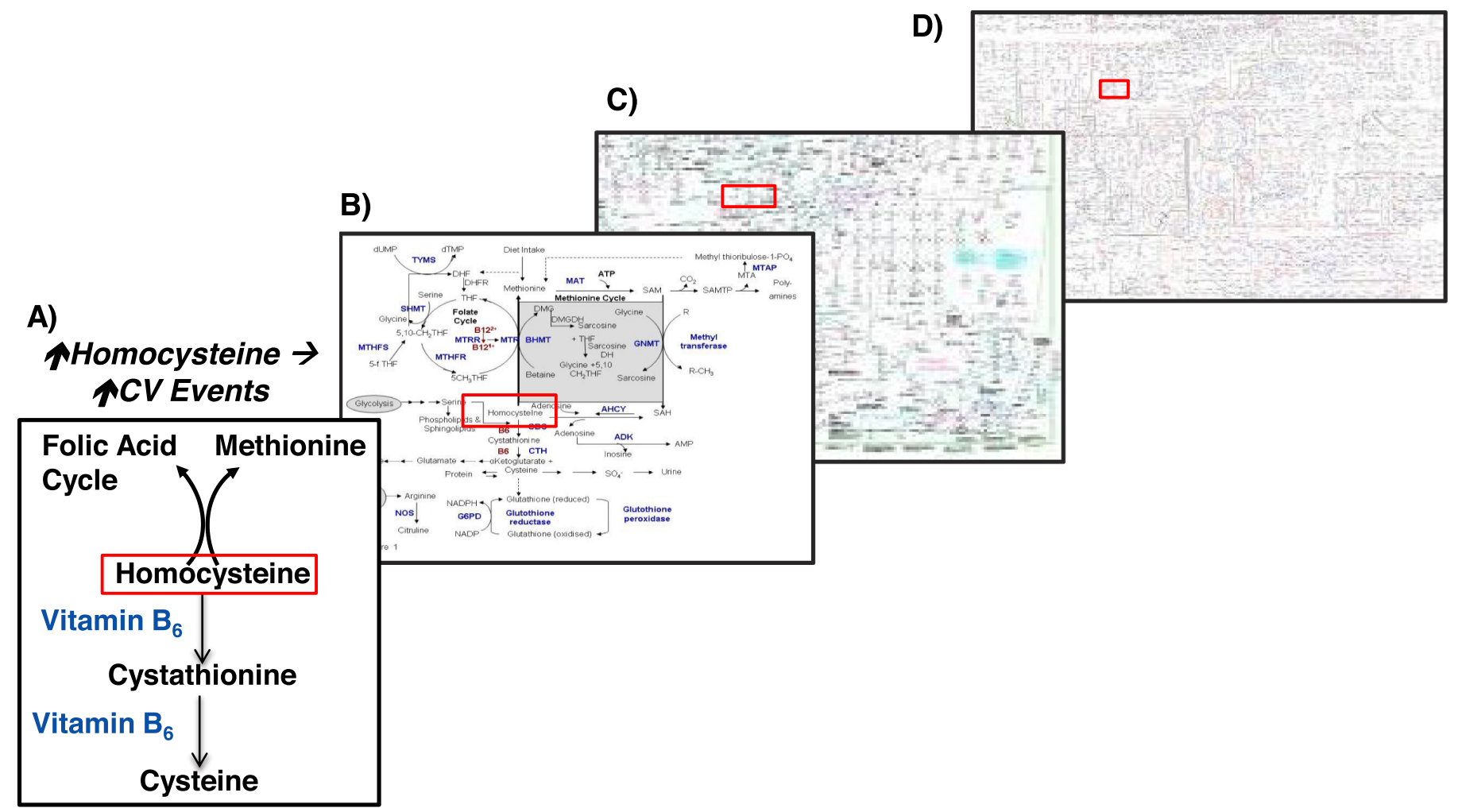

Figure 2. The biochemical pathway regulating homocysteine metabolism presented to scale within global mammalian metabolism. Despite numerous basic, translational, and epidemiological scientific reports establishing a link between hyperhomocysteinemia and cardiovascular disease risk, folic acid/B-vitamin supplementation to reduce plasma homocysteine levels is not associated with improved outcome in clinical trials. (A) Mechanistic data demonstrating the beneficial effects of folic acid/B-vitamins on homocysteine-induced vascular dysfunction are derived largely from studies focusing on factors directly relevant to homocysteine biochemistry. (B-D) However, this reductionist approach does not account for the consequences of folic acid or B-vitamins on off-target pathways that are connected to homocysteine and include intermediaries that regulate cell proliferation and survival. To consider the effects of folic acid/B-vitamins on homocysteine metabolism and other pathways, a systems level approach is required.

proteins follows a power law, which was a finding that was confirmed in a bacterium protein interactome, among other biological interactomes ${ }^{20}$. That is, a few nodes share the property of high connectivity, while a greater number of nodes share the property of low connectivity. These observations suggested that the relationship between nodes and link density in biological networks is not stochastic, but is based on non-random order. Indeed, subsequent work has demonstrated an inverse relationship between the number of nodes and the number of links associated with each node indicating that there is hierarchical order of connectivity with respect to function for nodes within a biological network ${ }^{19,21}$. Furthermore, the number of links correlates positively with the biological importance of a node, as removal of highly connected nodes corresponds to an increase in organism lethality ${ }^{19}$. This concept can be expressed by betweeness centrality, which reflects the number of shortest paths through a given node and is used to identify important or essential nodes within a network ${ }^{22,23}$. While this may seem to suggest that gene mutation (i.e., node deletion) is the principal driver of phenotype expression, this is, in fact, an uncommon occurrence ${ }^{24}$. By contrast, network perturbation that occurs through disruption of connectivity pathways via transcriptional, post-translational, and environmental effects is more likely to account for expression of complex diseases ${ }^{25-27}$.

Peri and colleagues constructed the first human protein interactome by establishing 24,385 binary protein-protein interactions, which was based on manual curation of the 
literature describing physical interactions between proteins discovered primarily from in vitro and in vivo experiments ${ }^{28}$. The same group later supplemented this database with novel protein-protein interactions derived from several additional protein databases ${ }^{29-31}$. They next analyzed the relationship between protein interactions according to subcellular compartment and their relative proximity within the network. They observed differences in connectivity patterns according to organelle and within specific biochemical pathways ${ }^{32}$. These findings contributed to a larger set of observations indicating that levels of organization within networks exist based on common biochemical, cellular, functional, and phenotypic threads ${ }^{33-36}$.

Subsequently, nomenclature for grouping based on ascending order of clustering scale has been proposed: node<hub<module<neighborhood, in which hubs represent highly connected nodes, modules define groups of highly connected nodes in close proximity to one another, and neighborhoods represent locally densely connected modules relative to the larger interactome ${ }^{37,38}$. These associations are commonly topographical (within the network), functional (in association with a common biochemical pathway), or diseaseassociated (related to a particular pathophenotype) ${ }^{6}$.

Recently, Menche and colleagues 39 focused attention on the validation of disease modules within the consolidated human interactome, which is a collection of all biologically relevant molecular interactions ${ }^{35,39-41}$. They compiled 141,296 physical interactions between 13,460 proteins derived from experimental data involving proteinprotein interactions and interactions along metabolic and kinase-substrate pathways. They next analyzed these data according to the relationship between pathways and 299 human diseases. By developing a mathematical code to abridge deficiency in the pool of known disease-associated genes, the investigators were able to identify disease modules while acknowledging that the current version of the consolidated human interactome remains incomplete (Figure 3). They observed that the position of two disease modules in this analysis was not random and, in fact, predicted biological and clinical similarities based on overlap between modules for gene ontology, gene co-expression, clinical symptoms, and probability of disease co-morbidity occurrence ${ }^{39}$. Taken together, these findings validate the translational relevance of molecular interaction mapping, illustrate the biological continuum spanning related pathophenotypes, and place into close proximity diseases considered previously to be unrelated (e.g., glioma and myocardial infarction).

\section{SYSTEMS BIOLOGY IN CARDIOVASCULAR MEDICINE}

\section{Coronary artery disease}

Reports leveraging systems biology to study the basis of human disease are populating the medical literature at an accelerating rate ${ }^{42}$, and include reports on chronic obstructive pulmonary disease ${ }^{43}$, solid tumor cancer ${ }^{44}$, gastrointestinal disorders 45 , and pharmacotherapeutics ${ }^{46}$ among other areas ${ }^{47}$. Most relevant to cardiovascular medicine, systems biology has been used to decipher the interactions between pathways that regulate inflammation, cell proliferation, apoptosis, thrombosis, and fibrosis in relation to diseases of the myocardium, pulmonary circulation, and systemic vasculature.

For example, Liu and colleagues performed a gene co-expression network analysis recently using publically available microarray data acquired from peripheral blood samples in patients with coronary artery disease (CAD) ${ }^{48}$. In this analysis, 3711 differentially expressed genes were segregated into 21 modules, and glucose-6phosphate dehydrogenase (G6PD) emerged as a highly connected node within 


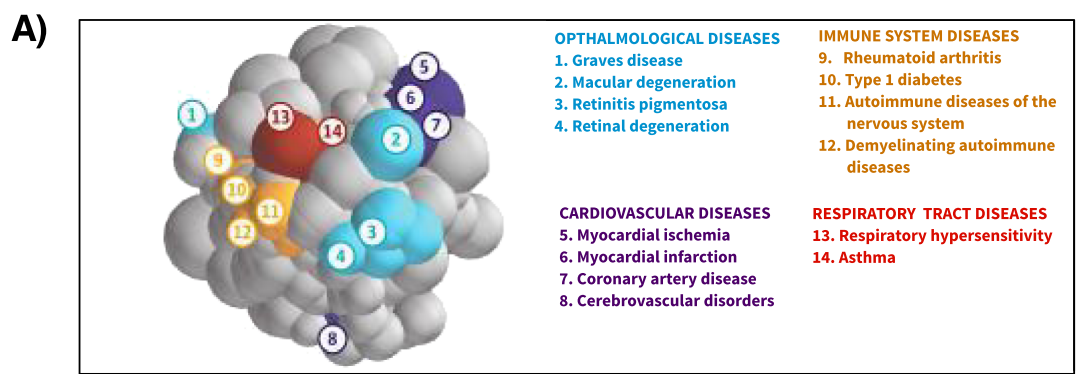

B)

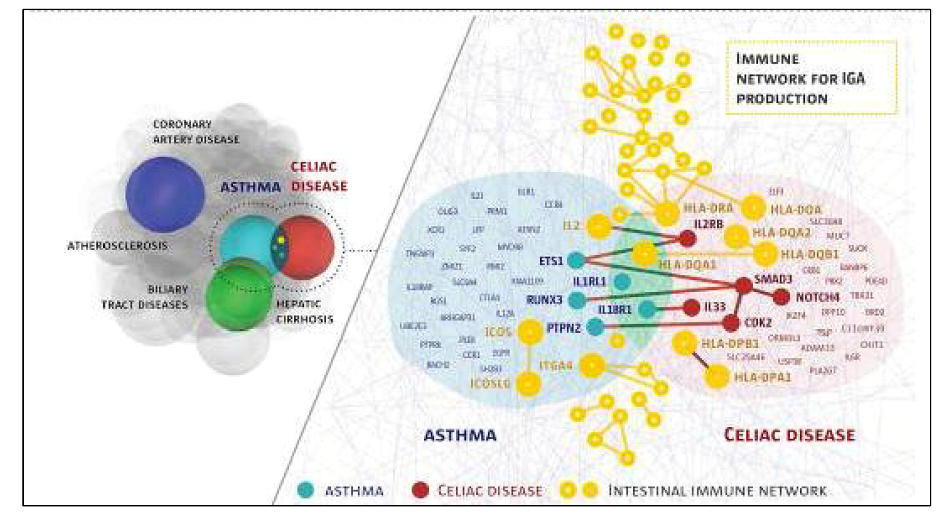

Figure 3. (A) A 3-dimensional representation of the relationship between diseases in the consolidated human interactome by Meche and colleagues ${ }^{39}$. In this analysis, the physical distance between diseases is proportional to the shortest distance between closely connected protein pairs across disease modules. Diseases whose modules (spheres) overlap are predicted to have a common molecular pathobiology. (B) This methodology identified unexpected overlap between certain diseases, such as hepatic cirrhosis, asthma, and celiac disease (left). A network-level map demonstrates the biological/immunological basis of overlap between in the asthma-celiac disease network-neighborhood. Figure and legend reproduced with some modifications from ${ }^{39}$ with permission pending.

the principal module. These data, which depict G6PD as an important hub in the pathogenesis of CAD, are in support of prior experimental data implicating deficient levels of this antioxidant enzyme as a cause of endothelial dysfunction, vascular stiffness, and systemic hypertension ${ }^{4-51}$. In related work from the Stockholm Atherosclerosis Gene Expression (STAGE) study, unbiased two-way clustering analytics performed on mRNA data from visceral fat and atherosclerotic lesions from patients was used to predict CAD severity ${ }^{2}$. The transendothelial migration of leukocytes (TEML) pathway as well as the LIM domain binding 2 protein emerged from this analysis as important targets linked to clinically expressed CAD, although confirmatory experimental data in support of these findings remain forthcoming.

Others have utilized networks for the purpose of determining prognosis following M153,54. The 'my-inflamome,' for example, is an interactome that included 2,595 proteins and 6,181 interactions based on seed genes related to inflammatory biomarkers used in the clinical management of MI patients ${ }^{55}$. From this, 21 highly-interconnected modules were described according to their association with key biological processes (e.g., posttranslational protein modification, apoptosis, etc.). Combinations of modules and highly connected nodes were entered into supervised computational and logistical regression analyses to identify Tissue Necrosis Factor- $\alpha$ associated factor (TRAF2), SHKBP binding protein-1 (SHKBP1), and Ubiquitin $\mathrm{B}(U B C)$ as genes that may prognosticate clinical outcome (defined as favorable [LVEF $>40 \%$ post-MI] vs. unfavorable [LVEF $<40 \%$ post-MI]).

Systems approaches are also being increasingly utilized to explore novel pathogenetic mechanisms underlying primary cardiomyopathies, including fibroblast-myocyte 
interactions ${ }^{56}$, the transcriptomic basis for cardiomyocyte remodeling 57 , biomarker identification in viral myocarditis ${ }^{8}$, and the proteomic basis of ischemic and reperfusion myocardial injury54,59. In some cases, systems biology has been leveraged to critically analyze data derived from genome-wide association studies (GWAS) reporting genetic variants in cardiomyopathy. For example, Backes and colleagues ${ }^{60}$ reviewed data on $\sim 280,000$ gene variants from 909 dilated cardiomyopathy patients and 2,120 controls, and identified enrichment pathways (using the Kyoto Encyclopedia of Genes and Genomes [KEGG] database) containing variants that were highly statistically significant between patient groups. From this analysis, focus was directed to nucleotide excision repair-related pathways. In particular, RAD23B, which regulates DNA damage recognition and base excision repair, emerged as a candidate gene in this analysis. However, the relevance of $\mathrm{RAD} 23 \mathrm{~B}$ or other genes implicated in this study to cardiomyopathy requires further validation experimentally.

\section{Pulmonary vascular disease}

Pulmonary hypertension is defined currently by a mean pulmonary artery pressure $\geq 25$ $\mathrm{mmHg}$ assessed by cardiac catheterization performed supine at rest ${ }^{61}$, and often occurs in the setting of left heart disease, parenchymal lung disease, or thromboembolism. Rarely, patients with PH that occurs due to interplay between molecular and genetic factors in the absence of other comorbidities are reclassified as having pulmonary arterial hypertension (PAH) ${ }^{62}$. In clinical practice, however, overlap between pulmonary hypertension sub-groups is common, which may confound diagnosis and treatment decision-making63,64. Therefore, there is an increasing emphasis on studying the molecular basis of pulmonary hypertension in order to delineate pulmonary vascular from other forms of cardiopulmonary diseases ${ }^{65,66}$, as well as to predict treatmentresponsiveness clinically ${ }^{67}$.

Systems biology has been utilized to characterize networks that regulate pulmonary vascular remodeling and the development of PAH. Activation of soluble guanylyl cyclase (sGC) by nitric oxide (NO) stimulates the conversion of GTP to cGMP, which, in turn, is a potent antimitogenic second messenger that promotes vascular smooth cell relaxation. Hydrolysis of cGMP to inactive 5'-GMP by phosphodiesterase type-V (PDE-V) is an endogenous counter-regulatory mechanism controlling NO bioactivity. However, diminished NO bioavailability and impaired NO-sGC signaling due, in part, to increased pulmonary vascular oxidant stress ${ }^{68}$ are associated with endothelial dysfunction, increased vascular smooth muscle cell proliferation, thrombosis, and vascular fibrosis that contribute to adverse vascular remodeling and pulmonary hypertension in $\mathrm{PAH}^{63}$. Although PDE-V inhibition and other novel direct NO delivery systems ${ }^{69}$ provide benefit to $\mathrm{PAH}$ patients ${ }^{70}$, the optimal strategy for inducing maximal NO bioactivity is not established. By modeling each step of the NO-sGC-cGMP reaction (12 molecular species and 12 rate constants), however, the effect of oxidation on single reactions, reaction pairs, or reaction trios was calculated recently to address this issue with respect to the NO-sGC-cGMP pathway in pulmonary artery smooth muscle cells (Figure 4). This approach identified sGC oxidation, NO dissociation from SGC, and PDE-mediated hydrolysis of cGMP as a collective is the principal enzymatic regulator of NO bioactivity in vitro, and sheds important new light on the potential value of a systems approach to pharmacology in cardiopulmonary disease ${ }^{71}$.

Systems biology has also been used to identify novel pathogenetic mechanisms controlling vascular remodeling in PAH. Parikh and colleagues generated a pulmonary hypertension network by mapping 131 published genes associated with the development 


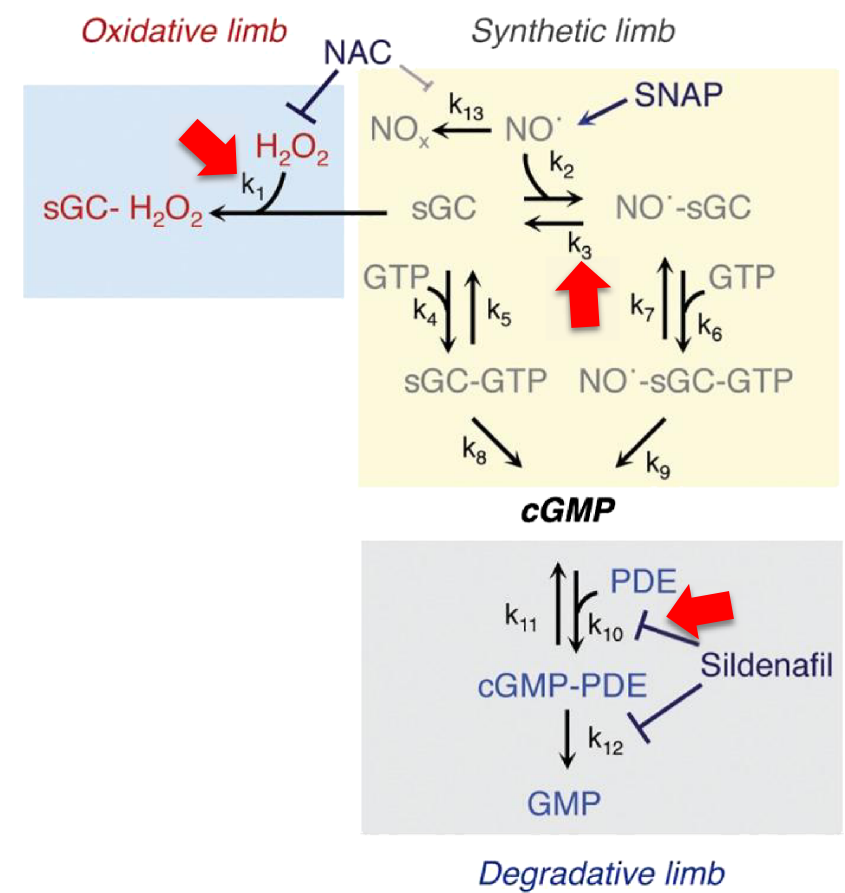

Figure 4. Nitric oxide-cGMP signaling. The vasodilator and anti-mitogenic molecule nitric oxide (NO) may be synthesized endogenously by upregulation of NO synthase enzymes or enzymatic conversion from nitrite, as well as exogenously by pharmacotherapeutic NO donors. The principal NO target in vascular cells is the heterodimeric enzyme soluble guanylyl cyclase (sGC), which converts GTP to the second messenger CGMP. Under conditions of increased oxidant stress, SGC may be oxidized to inhibit sGC sensing by NO that impairs normal NO-dependent vascular smooth muscle cell relaxation. Alternatively, cGMP may be hydrolyzed by phosphodiesterases to counter-regulate NO bioactivity. Predictions using a systems approach that considered reaction kinetic combinations for various steps in this biochemical pathway identified $k_{1}, k_{3}$, and $k_{10}$ (red arrows) collectively as an optimal target to modulate NO-cGMP signaling. cGMP, cyclic guanosine 3', 5'-monophosphate; GMP, guanosine-5'monophosphate; GTP, guanosine-5'-triphosphate; $\mathrm{H}_{2} \mathrm{O}_{2}$, hydrogen peroxide; $\mathrm{NAC}$, N-acetylcysteine; NO, nitric oxide; NOx, oxidized (inactive) nitrogen oxides; PDE, phosphodiesterase; SNAP, S-Nitroso$\mathrm{n}$-nacetylpenicillamine; sGC, soluble guanylyl cyclase. Adapted with some modifications from ${ }^{71}$ with permission pending.

of pulmonary hypertension to the consolidated human interactome ${ }^{72}$. An algorithmbased approach was then used to predict miRNA regulation of the $\mathrm{PH}$-associated genes, which allowed for rank-ordering of 29 miRNA groups based on their anticipated regulation of pulmonary hypertension-relevant pathways, which in this analysis involved gene sets associated with hypoxia, inflammation, and bone morphogenetic proteinsignaling. The investigators identified miR-21 targeting of Rho/Rho kinase from this approach as potentially relevant to pulmonary hypertension. This prediction was then validated by demonstrating miR-21-dependent upregulation of Rho/Rho kinase in cultured pulmonary endothelial cells, which corresponded to impaired endothelial nitric synthase expression in vitro and vascular remodeling and pulmonary hypertension in vivo. Similar approaches have been utilized to understand further mechanisms underpinning the fibrotic and the contractile vascular phenotype characteristics of $\mathrm{PAH}^{73-75}$.

\section{CONCLUSIONS}

The current era of scientific investigation, in which large-scale datasets are used to identify novel genetic or molecular etiologies for disease expression, has brought to 
light some limitations in the application of association studies and other reductionist analytical methods. Network theory is an evolving strategy that utilizes mathematical modeling to illustrate simultaneously numerous interactions between subcellular components. Discovering and reporting relationships based on hierarchical levels of connectivity assists in stratifying network nodes according to importance, and provides a scale-free model by which to pursue unexpected targets involved in disease pathobiology or treatment. Currently, systems biology methods have been reported across various areas within cardiovascular disease research, including coronary artery disease and pulmonary hypertension. Coupling this and other similar approaches with experimental methods to validate network findings is likely to increase the translational potential of observations in silico to clinically relevant findings for patients affected by cardiovascular disease.

\title{
COMPETING INTEREST
}

B.A.M.: Investigator initiated research supported by Gilead Sciences, Inc.

\section{FUNDING SOURCES}

This work was supported by 1Ko8HL11207-01A1, American Heart Association (AHA 15GRNT25080016), Pulmonary Hypertension Association, Cardiovascular Medical Research and Education Fund (CMREF), and Klarman Foundation at Brigham and Women's Hospital.

\section{AUTHOR CONTRIBUTIONS}

Bradley A. Maron and Jane A. Leopold contributed to the drafting of the manuscript and reviewed and revised it for critical content, and have given final approval to the manuscript version submitted for publication.

\author{
ABBREVIATIONS \\ miRNA microRNA \\ MI myocardial infarction \\ G6PD glucose-6-phosphate dehydrogenase \\ CAD coronary artery disease \\ KEGG Kyoto Encyclopedia of Genes and Genomes \\ GWAS genome-wide association study \\ PAH pulmonary arterial hypertension \\ NO nitric oxide \\ PDE phosphodiesterase \\ cGMP Cyclic guanosine monophosphate \\ GMP guanosine triphosphate \\ sGC soluble guanylyl cyclase
}

\section{REFERENCES}

[1] Loscalzo J. Association studies in an era of too much information: clinical analysis of new biomarker and genetic data. Circulation. 2007;116(17):1866-1870.

[2] Maron JL. The Neonatal Salivary Transcriptome. Cold Spring Harb Perspect Med. 2015;6(3).

[3] Quinn JF, Patel T, Wong D, Das S, Freedman JE, Laurent LC, Carter BS, Hochberg F, Van Keuren-Jensen K, Huentelman M, Spetzler R, Kalani MY, Arango J, Adelson PD, Weiner HL, Gandhi R, Goilav B, Putterman C, Saugstad JA. Extracellular RNAs: development as biomarkers of human disease. J Extracell Vesicles. 2015;4:27495. 
[4] Fox CS, Hall JL, Arnett DK, Ashley EA, Delles C, Engler MB, Freeman MW, Johnson JA, Lanfear DE, Liggett SB, Lusis AJ, Loscalzo J, MacRae CA, Musunuru K, Newby LK, O’Donnell C), Rich SS, Terzic A. Future translational applications from the contemporary genomics era: a scientific statement from the American Heart Association. Circulation. 2015;131(19):1715-1736.

[5] Do R, Stitziel NO, Won HH, Jorgensen AB, Duga S, Angelica Merlini P, Kiezun A, Farrall M, Goel A, Zuk O, Guella I, Asselta R, Lange LA, Peloso GM, Auer PL, Girelli D, Martinelli N, Farlow DN, DePristo MA, Roberts R, Stewart AF, Saleheen D, Danesh J, Epstein SE, Sivapalaratnam S, Hovingh GK, Kastelein J, Samani NJ, Schunkert H, Erdmann J, Shah SH, Kraus WE, Davies R, Nikpay M, Johansen CT, Wang J, Hegele RA, Hechter E, Marz W, Kleber ME, Huang J, Johnson AD, Li M, Burke GL, Gross M, Liu Y, Assimes TL, Heiss G, Lange EM, Folsom AR, Taylor HA, Olivieri O, Hamsten A, Clarke R, Reilly DF, Yin W, Rivas MA, Donnelly P, Rossouw JE, Psaty BM, Herrington DM, Wilson JG, Rich SS, Bamshad MJ, Tracy RP, Cupples LA, Rader DJ, Reilly MP, Spertus JA, Cresci S, Hartiala J, Tang WH, Hazen SL, Allayee H, Reiner AP, Carlson CS, Kooperberg C, Jackson RD, Boerwinkle E, Lander ES, Schwartz SM, Siscovick DS, McPherson R, Tybjaerg-Hansen A, Abecasis GR, Watkins H, Nickerson DA, Ardissino D, Sunyaev SR, O'Donnell C), Altshuler D, Gabriel S, Kathiresan S. Exome sequencing identifies rare LDLR and APOA5 alleles conferring risk for myocardial infarction. Nature. 2015;518(7537):102-106.

[6] Barabasi AL, Gulbahce N, Loscalzo J. Network medicine: a network-based approach to human disease. Nat Rev Genet. 2011;12(1):56-68.

[7] Kiani NA, Zenil H, Olczak J, Tegner J. Evaluating network inference methods in terms of their ability to preserve the topology and complexity of genetic networks. Semin Cell Dev Biol. 2016;51:44-52.

[8] Descartes R. The philosophical writings of Descartes. Vol 1. Cambridge: Cambridge University Press; 1985.

[9] Anderson PW. More is different. Science. 1972;177(4047):393-396.

[10] Khoury GA, Baliban RC, Floudas CA. Proteome-wide post-translational modification statistics: frequency analysis and curation of the swiss-prot database. Sci Rep. 2011;1.

[11] Maron BA, Zhang YY, White K, Chan SY, Handy DE, Mahoney CE, Loscalzo J, Leopold JA. Aldosterone inactivates the endothelin-B receptor via a cysteinyl thiol redox switch to decrease pulmonary endothelial nitric oxide levels and modulate pulmonary arterial hypertension. Circulation. 2012;126(8):963-974.

[12] Lee A, Oh JG, Gorski PA, Hajjar RJ, Kho C. Post-translational Modifications in Heart Failure: Small Changes, Big Impact. Heart Lung Circ. 2016;25(4):319-324.

[13] Muthusamy S, DeMartino AM, Watson LJ, Brittian KR, Zafir A, Dassanayaka S, Hong KU, Jones SP. MicroRNA-539 is up-regulated in failing heart, and suppresses O-GIcNAcase expression. J Biol Chem. 2014;289(43):29665-29676.

[14] Lonn E, Yusuf S, Arnold MJ, Sheridan P, Pogue J, Micks M, McQueen MJ, Probstfield J, Fodor G, Held C, Genest Jr J. Homocysteine lowering with folic acid and B vitamins in vascular disease. N Engl I Med. 2006;354(15):1567-1577.

[15] Maron BA, Loscalzo J. The treatment of hyperhomocysteinemia. Annu Rev Med. 2009;60:39-54.

[16] Ulrich CM. Folate and cancer prevention: a closer look at a complex picture. Am J Clin Nutr. 2007;86(2):271-273.

[17] Bonaa KH, Njolstad I, Ueland PM, Schirmer H, Tverdal A, Steigen T, Wang H, Nordrehaug JE, Arnesen E, Rasmussen K. Homocysteine lowering and cardiovascular events after acute myocardial infarction. $N$ Engl J Med. 2006;354(15):1578-1588.

[18] Albert R, Barabasi AL. Statistical mechanics of complex networks. Rev Mod Phys. 2002;74:47-97.

[19] Jeong H, Mason SP, Barabasi AL, Oltvai ZN. Lethality and centrality in protein networks. Nature. 2001;411(6833):41-42.

[20] Rain JC, Selig L, De Reuse H, Battaglia V, Reverdy C, Simon S, Lenzen G, Petel F, Wojcik J, Schachter V, Chemama Y, Labigne A, Legrain P. The protein-protein interaction map of Helicobacter pylori. Nature. 2001;409(6817):211-215.

[21] Jeong H, Tombor B, Albert R, Oltvai ZN, Barabasi AL. The large-scale organization of metabolic networks. Nature. 2000;407(6804):651-654.

[22] Yu H, Kim PM, Sprecher E, Trifonov V, Gerstein M. The importance of bottlenecks in protein networks: correlation with gene essentiality and expression dynamics. PLoS Comput Biol. 2007;3(4):e59.

[23] Freeman LC. A set of measures of centrality based on betweenness. Sociometry. 1977;40:35-41.

[24] Silverman EK, Loscalzo J. Network medicine approaches to the genetics of complex diseases. Discov Med. 2012;14(75):143-152.

[25] Goh KI, Cusick ME, Valle D, Childs B, Vidal M, Barabasi AL. The human disease network. Proc Natl Acad Sci USA. 2007;104(21):8685-8690.

[26] Pawson T, Linding R. Network medicine. FEBS Lett. 2008;582(8):1266-1270.

[27] Schadt EE. Molecular networks as sensors and drivers of common human diseases. Nature. 2009;461(7261):218-223.

[28] Peri S, Navarro JD, Amanchy R, Kristiansen TZ, Jonnalagadda CK, Surendranath V, Niranjan V, Muthusamy B, Gandhi TK, Gronborg M, Ibarrola N, Deshpande N, Shanker K, Shivashankar HN, Rashmi BP, Ramya MA, Zhao Z, Chandrika KN, Padma N, Harsha HC, Yatish AJ, Kavitha MP, Menezes M, Choudhury DR, Suresh S, Ghosh N, Saravana R, Chandran S, Krishna S, Joy M, Anand SK, Madavan V, Joseph A, Wong GW, Schiemann WP, Constantinescu SN, Huang L, Khosravi-Far R, Steen H, Tewari M, Ghaffari S, Blobe GC, Dang CV, Garcia JG, Pevsner J, Jensen ON, Roepstorff P, Deshpande KS, Chinnaiyan 
AM, Hamosh A, Chakravarti A, Pandey A. Development of human protein reference database as an initial platform for approaching systems biology in humans. Genome Res. 2003;13(10):2363-2371.

[29] Salwinski L, Miller CS, Smith AJ, Pettit FK, Bowie JU, Eisenberg D. The Database of Interacting Proteins: 2004 update. Nucleic Acids Res. 2004;32(Database issue):D449-451.

[30] Zanzoni A, Montecchi-Palazzi L, Quondam M, Ausiello G, Helmer-Citterich M, Cesareni G. MINT: a Molecular INTeraction database. FEBS Lett. 2002;513(1):135-140.

[31] Pagel P, Kovac S, Oesterheld M, Brauner B, Dunger-Kaltenbach I, Frishman G, Montrone C, Mark P, Stumpflen V, Mewes HW, Ruepp A, Frishman D. The MIPS mammalian protein-protein interaction database. Bioinformatics. 2005;21(6):832-834.

[32] Gandhi TK, Zhong J, Mathivanan S, Karthick L, Chandrika KN, Mohan SS, Sharma S, Pinkert S, Nagaraju S, Periaswamy B, Mishra G, Nandakumar K, Shen B, Deshpande N, Nayak R, Sarker M, Boeke JD, Parmigiani G, Schultz J, Bader JS, Pandey A. Analysis of the human protein interactome and comparison with yeast, worm and fly interaction datasets. Nat Genet. 2006;38(3):285-293.

[33] Suthram S, Dudley JT, Chiang AP, Chen R, Hastie TJ, Butte AJ. Network-based elucidation of human disease similarities reveals common functional modules enriched for pluripotent drug targets. PLoS Comput Biol. 2010;6(2):e1000662.

[34] Liu Yl, Wise PH, Butte AJ. The "etiome": identification and clustering of human disease etiological factors. BMC Bioinformatics. 2009;10(Suppl 2):S14.

[35] Chuang HY, Lee E, Liu YT, Lee D, Ideker T. Network-based classification of breast cancer metastasis. Mol Syst Biol. 2007:3:140.

[36] Calvano SE, Xiao W, Richards DR, Felciano RM, Baker HV, Cho RJ, Chen RO, Brownstein BH, Cobb JP, Tschoeke SK, Miller-Graziano C, Moldawer LL, Mindrinos MN, Davis RW, Tompkins RG, Lowry SF. A network-based analysis of systemic inflammation in humans. Nature. 2005;437(7061):1032-1037.

[37] Barabasi AL, Bonabeau E. Scale-free networks. Sci Am. 2003;288(5):60-69.

[38] Girvan M, Newman ME. Community structure in social and biological networks. Proc Natl Acad Sci USA. 2002;99(12):7821-7826.

[39] Menche J, Sharma A, Kitsak M, Ghiassian SD, Vidal M, Loscalzo J, Barabasi AL. Disease networks. Uncovering disease-disease relationships through the incomplete interactome. Science. 2015;347(6224):1257601.

[40] Lage K, Mollgard K, Greenway S, Wakimoto H, Gorham JM, Workman CT, Bendsen E, Hansen NT, Rigina O, Roque FS, Wiese C, Christoffels VM, Roberts AE, Smoot LB, Pu WT, Donahoe PK, Tommerup N, Brunak S, Seidman CE, Seidman JG, Larsen LA. Dissecting spatio-temporal protein networks driving human heart development and related disorders. Mol Syst Biol. 2010;6:381.

[41] Mosca R, Pons T, Ceol A, Valencia A, Aloy P. Towards a detailed atlas of protein-protein interactions. Curr Opin Struct Biol. 2013;23(6):929-940.

[42] Rzhetsky A, Wajngurt D, Park N, Zheng T. Probing genetic overlap among complex human phenotypes. Proc Natl Acad Sci USA. 2007;104(28):11694-11699.

[43] Davidsen PK, Herbert JM, Antczak P, Clarke K, Ferrer E, Peinado VI, Gonzalez C, Roca J, Egginton S, Barbera JA, Falciani F. A systems biology approach reveals a link between systemic cytokines and skeletal muscle energy metabolism in a rodent smoking model and human COPD. Genome Med. 2014;6(8):59.

[44] Gamez-Pozo A, Perez Carrion RM, Manso L, Crespo C, Mendiola C, Lopez-Vacas R, Berges-Soria J, Lopez IA, Margeli M, Calero JL, Farre XG, Santaballa A, Ciruelos EM, Afonso R, Lao J, Catalan G, Gallego JV, Lopez JM, Bofill FJ, Borrego MR, Espinosa E, Vara JA, Zamora P. The Long-HER study: clinical and molecular analysis of patients with HER2 + advanced breast cancer who become long-term survivors with trastuzumab-based therapy. PLoS ONE. 2014;9(10):e109611.

[45] Gevers D, Kugathasan S, Denson LA, Vazquez-Baeza Y, Van Treuren W, Ren B, Schwager E, Knights D, Song SJ, Yassour M, Morgan XC, Kostic AD, Luo C, Gonzalez A, McDonald D, Haberman Y, Walters T, Baker S, Rosh J, Stephens M, Heyman M, Markowitz J, Baldassano R, Griffiths A, Sylvester F, Mack D, Kim S, Crandall W, Hyams J, Huttenhower C, Knight R, Xavier RJ. The treatment-naive microbiome in newonset Crohn's disease. Cell Host Microbe. 2014;15(3):382-392.

[46] Farkas IJ, Korcsmaros T, Kovacs IA, Mihalik A, Palotai R, Simko GI, Szalay KZ, Szalay-Beko M, Vellai T, Wang S, Csermely P. Network-based tools for the identification of novel drug targets. Sci Signal. 2011;4(173):pt3.

[47] Wang RS, Loscalzo J. Illuminating drug action by network integration of disease genes: a case study of myocardial infarction. Mol Biosyst. 2016.

[48] Liu J, Jing L, Tu X. Weighted gene co-expression network analysis identifies specific modules and hub genes related to coronary artery disease. BMC Cardiovasc Disord. 2016;16(1):54.

[49] Leopold JA, Dam A, Maron BA, Scribner AW, Liao R, Handy DE, Stanton RC, Pitt B, Loscalzo J. Aldosterone impairs vascular reactivity by decreasing glucose-6-phosphate dehydrogenase activity. Nat Med. 2007:13(2):189-197.

[50] Leopold JA, Walker J, Scribner AW, Voetsch B, Zhang YY, Loscalzo AJ, Stanton RC, Loscalzo J. Glucose-6phosphate dehydrogenase modulates vascular endothelial growth factor-mediated angiogenesis. J Biol Chem. 2003;278(34):32100-32106.

[51] Leopold JA, Zhang YY, Scribner AW, Stanton RC, Loscalzo J. Glucose-6-phosphate dehydrogenase overexpression decreases endothelial cell oxidant stress and increases bioavailable nitric oxide. Arterioscler Thromb Vasc Biol. 2003;23(3):411-417. 
[52] Hagg S, Skogsberg J, Lundstrom J, Noori P, Nilsson R, Zhong H, Maleki S, Shang MM, Brinne B, Bradshaw M, Bajic VB, Samnegard A, Silveira A, Kaplan LM, Gigante B, Leander K, de Faire U, Rosfors S, Lockowandt U, Liska J, Konrad P, Takolander R, Franco-Cereceda A, Schadt EE, Ivert T, Hamsten A, Tegner J, Bjorkegren J. Multi-organ expression profiling uncovers a gene module in coronary artery disease involving transendothelial migration of leukocytes and LIM domain binding 2: the Stockholm Atherosclerosis Gene Expression (STAGE) study. PLoS Genet. 2009;5(12):e1000754.

[53] Basak T, Varshney S, Akhtar S, Sengupta S. Understanding different facets of cardiovascular diseases based on model systems to human studies: a proteomic and metabolomic perspective. J Proteomics. 2015;127(Pt A):50-60.

[54] Vilahur G, Cubedo J, Casani L, Padro T, Sabate-Tenas M, Badimon JJ, Badimon L. Reperfusion-triggered stress protein response in the myocardium is blocked by post-conditioning. Systems biology pathway analysis highlights the key role of the canonical aryl-hydrocarbon receptor pathway. Eur Heart J. 2013;34(27):2082-2093.

[55] Azuaje FJ, Rodius S, Zhang L, Devaux Y, Wagner DR. Information encoded in a network of inflammation proteins predicts clinical outcome after myocardial infarction. BMC Med Genomics. 2011;4:59.

[56] Brown TR, Krogh-Madsen T, Christini DJ. Computational Approaches to Understanding the Role of Fibroblast-Myocyte Interactions in Cardiac Arrhythmogenesis. Biomed Res Int. 2015;2015:465714.

[57] Shih YH, Zhang Y, Ding Y, Ross CA, Li H, Olson TM, Xu X. Cardiac transcriptome and dilated cardiomyopathy genes in zebrafish. Circ Cardiovasc Genet. 2015;8(2):261-269.

[58] Omura S, Kawai E, Sato F, Martinez NE, Chaitanya GV, Rollyson PA, Cvek U, Trutschl M, Alexander JS, Tsunoda I. Bioinformatics multivariate analysis determined a set of phase-specific biomarker candidates in a novel mouse model for viral myocarditis. Circ Cardiovasc Genet. 2014;7(4):444-454.

[59] Chen CH, Budas GR, Churchill EN, Disatnik MH, Hurley TD, Mochly-Rosen D. Activation of aldehyde dehydrogenase-2 reduces ischemic damage to the heart. Science. 2008;321(5895):1493-1495.

[6o] Backes C, Meder B, Lai A, Stoll M, Ruhle F, Katus HA, Keller A. Pathway-based variant enrichment analysis on the example of dilated cardiomyopathy. Hum Genet. 2016;135(1):31-40.

[61] Maron BA, Hess E, Maddox TM, Opotowsky AR, Tedford RJ, Lahm T, Joynt KE, Kass DJ, Stephens T, Stanislawski MA, Swenson ER, Goldstein RH, Leopold JA, Zamanian RT, Elwing JM, Plomondon ME, Grunwald GK, Baron AE, Rumsfeld JS, Choudhary G. Association of Borderline Pulmonary Hypertension With Mortality and Hospitalization in a Large Patient Cohort: Insights From the Veterans Affairs Clinical Assessment, Reporting, and Tracking Program. Circulation. 2016;133(13):1240-1248.

[62] Humbert M, Montani D, Evgenov OV, Simonneau G. Definition and classification of pulmonary hypertension. Handb Exp Pharmacol. 2013;218:3-29.

[63] Maron BA, Loscalzo J. Pulmonary hypertension: pathophysiology and signaling pathways. Handb Exp Pharmacol. 2013;218:31-58.

[64] Choudhary G, Jankowich M, Wu WC. Prevalence and clinical characteristics associated with pulmonary hypertension in African-Americans. PLoS ONE. 2014;8(12):e84264.

[65] Chesne J, Danger R, Botturi K, Reynaud-Gaubert M, Mussot S, Stern M, Danner-Boucher I, Mornex JF, Pison C, Dromer C, Kessler R, Dahan M, Brugiere O, Le Pavec J, Perros F, Humbert M, Gomez C, Brouard $\mathrm{S}$, Magnan A. Systematic analysis of blood cell transcriptome in end-stage chronic respiratory diseases. PLOS ONE. 2014;9(10):e109291.

[66] Wu W, Dave NB, Yu G, Strollo PJ, Kovkarova-Naumovski E, Ryter SW, Reeves SR, Dayyat E, Wang Y, Choi AM, Gozal D, Kaminski N. Network analysis of temporal effects of intermittent and sustained hypoxia on rat lungs. Physiol Genomics. 2008;36(1):24-34.

[67] Hemnes AR, Trammell AW, Archer SL, Rich S, Yu C, Nian H, Penner N, Funke M, Wheeler L, Robbins IM, Austin ED, Newman JH, West J. Peripheral blood signature of vasodilator-responsive pulmonary arterial hypertension. Circulation. 2015;131(4):401-409; discussion 409.

[68] Maron BA, Zhang YY, Handy DE, Beuve A, Tang SS, Loscalzo J, Leopold JA. Aldosterone increases oxidant stress to impair guanylyl cyclase activity by cysteinyl thiol oxidation in vascular smooth muscle cells. J Biol Chem. 2009;284(12):7665-7672.

[69] Mohamed NA, Ahmetaj-Shala B, Duluc L, Mackenzie LS, Kirkby NS, Reed DM, Lickiss PD, Davies RP, Freeman GR, Wojciak-Stothard B, Chester AH, El-Sherbiny IM, Mitchell JA, Yacoub MH. A New NOReleasing Nanoformulation for the Treatment of Pulmonary Arterial Hypertension. J Cardiovasc Trans/ Res. 2016.

[70] Barst RJ, Ivy DD, Gaitan G, Szatmari A, Rudzinski A, Garcia AE, Sastry BK, Pulido T, Layton GR, SerdarevicPehar M, Wessel DL. A randomized, double-blind, placebo-controlled, dose-ranging study of oral sildenafil citrate in treatment-naive children with pulmonary arterial hypertension. Circulation. 2008;125(2):324-334.

[71] Garmaroudi FS, Handy DE, Liu YY, Loscalzo J. Systems Pharmacology and Rational Polypharmacy: Nitric Oxide-Cyclic GMP Signaling Pathway as an Illustrative Example and Derivation of the General Case. PLoS Comput Biol. 2016;12(3):e1004822.

[72] Parikh VN, Jin RC, Rabello S, Gulbahce N, White K, Hale A, Cottrill KA, Shaik RS, Waxman AB, Zhang YY, Maron BA, Hartner JC, Fujiwara Y, Orkin SH, Haley KJ, Barabasi AL, Loscalzo J, Chan SY. MicroRNA-21 integrates pathogenic signaling to control pulmonary hypertension: results of a network bioinformatics approach. Circulation. 2012;125(12):1520-1532.

[73] Bertero T, Cottrill K, Krauszman A, Lu Y, Annis S, Hale A, Bhat B, Waxman AB, Chau BN, Kuebler WM, Chan SY. The microRNA-130/301 family controls vasoconstriction in pulmonary hypertension. J Biol Chem. 2015;290(4):2069-2085. 
[74] Bertero T, Cottrill KA, Annis S, Bhat B, Gochuico BR, Osorio JC, Rosas I, Haley KJ, Corey KE, Chung RT, Nelson Chau B, Chan SY. A YAP/TAZ-miR-130/301 molecular circuit exerts systems-level control of fibrosis in a network of human diseases and physiologic conditions. Sci Rep. 2015;5:18277.

[75] Kim JD, Lee A, Choi J, Park Y, Kang H, Chang W, Lee MS, Kim J. Epigenetic modulation as a therapeutic approach for pulmonary arterial hypertension. Exp Mol Med. 2015;47:e175. 